\title{
Norharman and Harman in Human Urine
}

\author{
By Hirofumi Ushiyama, ${ }^{*)}$ Atsuko OGURI, ${ }^{* *)}$ Yukari Totsuka, ${ }^{* *)}$ Hajime IToH, ${ }^{* * *)}$ \\ Takashi SugimuRA, M. J. A., ${ }^{* *)}$ and Keiji WaKABAYASHI**),†
}

(Communicated Jan. 12, 1995)

\begin{abstract}
It has been shown that norharman and harman, present in our environment, may act as genotoxic compounds in human body. In order to have an insight of the extents of exposure to these $\beta$-carbolines, we measured their levels in human urine. Samples of 24 -hr urine were collected from ten healthy volunteers eating a normal diet and three patients receiving parenteral alimentation. The urine samples were separated by blue cotton treatment, cation exchange IONEX column chromatography and HPLC on a semi-preparative ODS column. The contents of norharman and harman in the partially purified materials were determined by HPLC with a fluorometric detector. Norharman and harman were detected in all 24-hr urine samples from healthy volunteers at levels of 9.3-33.5 $\mathrm{ng}$ and 97.7-298 $\mathrm{ng}$, respectively. These $\beta$-carbolines were also found to be present in the urine of the three patients and their levels in the 24-hr urine were comparatively lower than those in urine of healthy volunteers eating normal diet. After changing from parenteral alimentation to diet, the two $\beta$-carboline levels in urine increased in two of the three patients. From the above results, it is suggested that humans are continuously exposed to norharman and harman derived endogenously and exogenously.
\end{abstract}

Key words : Norharman; harman; comutagen; human urine.

$\beta$-Carboline compounds, norharman ( $9 H$-pyrido$[3,4-b]$ indole) and harman (1-methyl-9H-pyrido[3,4$b$ ]indole), are produced by heating L-tryptophan, ${ }^{1)}$ and are known to be present in cigarette smoke condensate $^{2)}$ and cooked foods. ${ }^{3)}$ Norharman is not mutagenic to Salmonella typhimurium TA98 and TA100 with or without metabolic activation system (S9 mix). Aniline, o-toluidine and yellow $\mathrm{OB}$ are carcinogenic but not mutagenic to $S$. typhimurium strains. However, these carcinogenic aromatic amines are demonstrated to be mutagenic to $S$. typhimurium TA98 with S9 mix in the presence of norharman. ${ }^{4), 5)}$ Thus, norharman is called a comutagen. Similarly, harman shows comutagenicity, but has weaker activity as compared to that of norharman. It has been

*) Division of Food Hygiene, The Tokyo Metropolitan Research Laboratory of Public Health, 3-24-1 Hyakunincho, Shinjuku-ku, Tokyo 169, Japan.

**) Biochemistry Division, National Cancer Center Research Institute, 5-1-1 Tsukiji, Chuo-ku, Tokyo 104, Japan.

***) Department of Clinical Chemistry, Kitasato University School of Hygienic Sciences, 1-15-1 Kitasato, Sagamihara 228, Japan.

†) Correspondence to: K. Wakabayashi. reported that norharman and harman show mutagenicity toward Chinese hamster lung cells with diphtheria toxin resistance as a marker ${ }^{6}$ and induce sisterchromatid exchanges in human peripheral lymphocytes. $^{7,8)}$ Moreover, these $\beta$-carbolines were found to form DNA adducts in mice when given at $0.1 \%$ in their diet for four weeks. ${ }^{9)}$ These observations suggest that norharman and harman may act as genotoxic compounds to humans by themselves. It is important to determine the extents of human exposure to these $\beta$-carbolines. Therefore, the levels of norharman and harman in human urine were measured in the present study.

We previously reported that four carcinogenic heterocyclic amines, 2-amino-3,8-dimethylimidazo[4,5$f$ ]quinoxaline (MeIQx), 2-amino-1-methyl-6-phenylimidazo[4,5-b]pyridine (PhIP), 3-amino-1,4-dimethyl-5Hpyrido[4,3-b]indole (Trp-P-1) and 3-amino-1-methyl$5 H$-pyrido[4,3-b]indole (Trp-P-2), were detected in samples of 24-hr urine from ten healthy volunteers, five males and five females eating a normal diet, but not in those from three patients receiving parenteral alimentation. ${ }^{10)}$ In the present study, norharman and harman were analyzed using the same samples of 
Table I. Amounts of norharman and harman in human urine

\begin{tabular}{|c|c|c|c|c|c|c|}
\hline \multirow{3}{*}{ Subject } & \multirow{3}{*}{$\begin{array}{c}\text { Age } \\
\text { (years) }\end{array}$} & \multirow{3}{*}{ Sex } & \multicolumn{4}{|c|}{ Amount (ng/24-hr urine) } \\
\hline & & & \multicolumn{2}{|c|}{ Norharman } & \multicolumn{2}{|c|}{ Harman } \\
\hline & & & $\begin{array}{l}\text { Parenteral } \\
\text { alimentation }\end{array}$ & $\begin{array}{c}\text { Diet } \\
\text { ingestion }\end{array}$ & $\begin{array}{l}\text { Parenteral } \\
\text { alimentation }\end{array}$ & $\begin{array}{c}\text { Diet } \\
\text { ingestion }\end{array}$ \\
\hline I & 13 & $\mathrm{~F}$ & & 16.7 & & 165 \\
\hline II & 32 & $\mathrm{~F}$ & & 22.3 & & 172 \\
\hline III & 33 & M & & 12.6 & & 97.7 \\
\hline IV & 35 & M & & 9.3 & & 259 \\
\hline $\mathrm{V}$ & 35 & M & & 20.8 & & 201 \\
\hline VI & 41 & $\mathrm{~F}$ & & 18.6 & & 298 \\
\hline VII & 42 & M & & 18.6 & & 122 \\
\hline VIII & 49 & $\mathrm{~F}$ & & 33.5 & & 110 \\
\hline IX & 67 & $\mathrm{~F}$ & & 12.1 & & 184 \\
\hline $\mathrm{X}$ & 80 & M & & 14.5 & & 139 \\
\hline XI & 63 & M & 14.7 & 24.3 & 274 & 356 \\
\hline XII & 64 & M & 9.0 & 6.4 & 133 & 64.9 \\
\hline XIII & 58 & $\mathrm{~F}$ & 6.9 & 11.8 & 32.4 & 63.7 \\
\hline
\end{tabular}

Subjects I-X are healthy volunteers consuming normal diet and subjects III, VII and X are smokers. Subject XI underwent an operation for prostate cancer, subject XII an operation for renal cancer, and subject XIII an operation for urothelial cancer. These patients received parenteral alimentation for 1 day before, and 4 days after operation. After cessation of parenteral alimentation, the patients ate diet for 4 days.

urines from ten healthy volunteers and three patients. Moreover, levels of $\beta$-carbolines in urine from the three patients, who had parenteral alimentation and then changed to diet, were also measured.

Table I shows the ages and sexes of the thirteen subjects. Samples of $24-\mathrm{hr}$ urine were partially purified by blue cotton treatment, a cation exchange TIN-100 H05E fiber column chromatography and HPLC on a semi-preparative ODS column as described previously. ${ }^{10)}$ The fractions corresponding to the retention times of authentic norharman and harman (16-17 min for norharman and 20-21 min for harman) were collected and evaporated to dryness. The resulting samples were dissolved in $200 \mu \mathrm{l}$ of $50 \%$ methanol and aliquots were subjected to HPLC on a cation exchange TSKgel SP-2SW column ( $5 \mu \mathrm{m}$ particle size, $4.6 \times 250 \mathrm{~mm}$, Tosoh Corp., Tokyo). The material was eluted with $40 \%$ acetonitrile in $100 \mathrm{mM}$ phosphate buffer $(\mathrm{pH} 3.0)$ at a flow rate of $1.0 \mathrm{ml} / \mathrm{min}$ at the ambient temperature. Norharman and harman were detected by their fluorescence with excitation and emission wavelength of $260 \mathrm{~nm}$ and $430 \mathrm{~nm}$, respectively. Fluorescence peaks corresponding to the retention times of norharman and harman were detected in all urine samples not only from healthy volunteers but also from patients. The peak fractions containing norharman and harman were each collected and further analyzed on a YMC A303 ODS column (5 $\mu \mathrm{m}$ particle size, $4.6 \times 250 \mathrm{~mm}$, Yamamura Chemical Laboratories, Kyoto). When a mobile phase of $25 \%$ acetonitrile in $25 \mathrm{mM}$ phosphate buffer ( $\mathrm{pH} 2.0$ ) was pumped in at a flow rate of $0.8 \mathrm{ml} / \mathrm{min}$, norharman and harman were clearly seen as a single peak at retention times of $9 \mathrm{~min}$ and $12 \mathrm{~min}$, respectively, in all the samples. Typical chromatograms of norharman in the urine of subject V on SP-2SW and ODS columns are shown in Fig. 1A and B, respectively. The recoveries of norharman and harman during the purification process were estimated by spiking with an equivalent level of authentic $\beta$-carbolines to those detected in urine, and their values were found to be 50.4 and $61.0 \%$, respectively.

The above HPLC procedures were repeated several times, and the UV and fluorescence emission spectra of the collected peak fractions having the same retention times as norharman and harman on the analytical ODS column were analyzed with an SPDM6A photodiode array detector (Shimadzu Corp., Kyoto) and an FS-8011 fluorometric detector (Tosoh Corp.), respectively. The UV-absorption pattern and fluorescence emission spectra of the compounds analyzed were identical with those of the authentic com- 

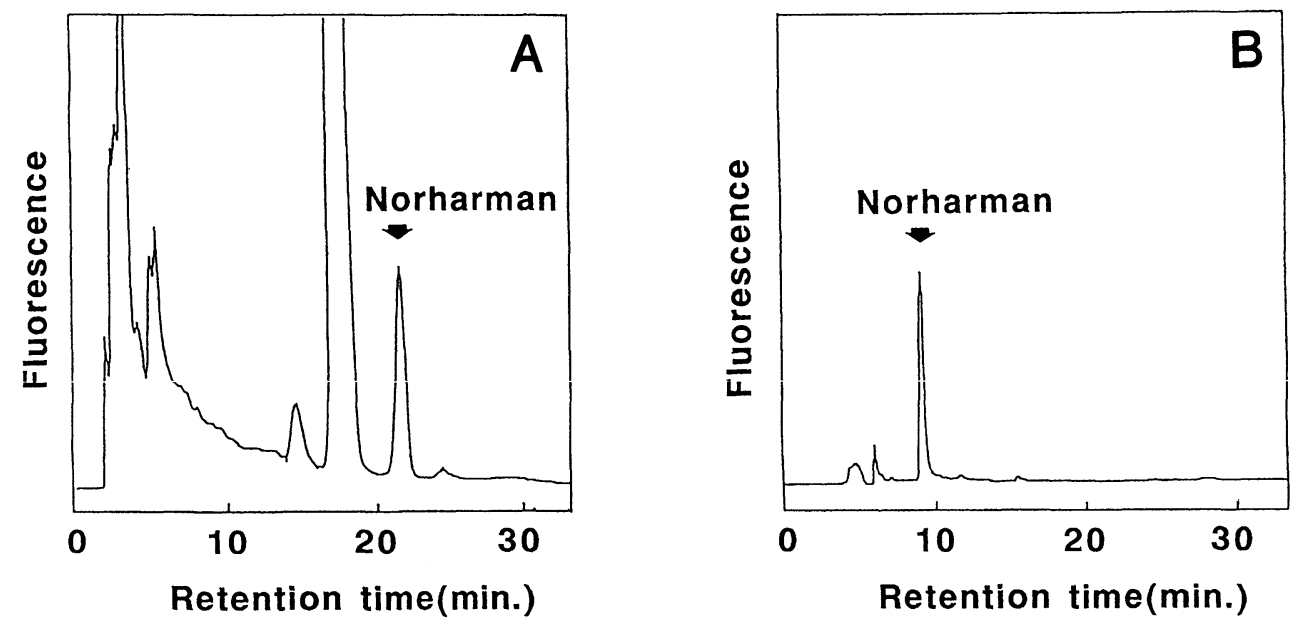

Fig. 1. HPLC chromatograms of norharman in urine sample from subject $\mathrm{V}$ on an SP-2SW column and on an ODS column. The peak fraction that coincided in position with that of authentic norharman on the SP-2SW column (A) was collected, and further analyzed on the ODS column (B). The eluates were monitored by their fluorescence with excitation and emission wavelengths of 260 and $430 \mathrm{~nm}$, respectively. The peak fractions corresponding to the retention time of authentic norharman on the two columns are indicated by arrows.

pounds. Thus, the compounds detected by HPLC were confirmed to be norharman and harman.

By correcting the amounts of these $\beta$-carbolines detected by HPLC for their recoveries, the levels in 24-hr urine samples were calculated and shown in Table I. The levels of $\beta$-carbolines in 24-hr urine samples from healthy volunteers (subjects I-X) were 9.3-33.5 ng for norharman and 97.7-298 ng for harman. Three of the volunteers were smokers; subject III smoked 40-45 cigarettes/day, and subjects VII and $\mathrm{X}$ smoked 15-20 cigarettes/day. Norharman and harman are reported to be present in mainstream smoke condensates at levels of 12.3-14.1 $\mu \mathrm{g}$ and 3.3-5.8 $\mu \mathrm{g}$ per cigarette, respectively. ${ }^{2)}$ However, no significant influence of cigarette smoking on the level of these $\beta$-carbolines in urine was observed. In addition, norharman and harman were also detected in urine samples from all three patients receiving parenteral alimentation for 1 day before and 4 days after surgery and their levels in 24-hr urine were 6.9-14.7 $\mathrm{ng}$ and $32.4-274 \mathrm{ng}$, respectively. It is noteworthy that the alimentation solution consisting of sugars, salts and vitamins did not contain the two $\beta$-carbolines. From these results, it is strongly suggested that norharman and harman are probably produced endogenously in human body. This is supported by a report that harman is proposed to be formed from L-tryptophan and acetyl-CoA in a plant, Passiflora edulis. ${ }^{11)}$

The levels of norharman and harman in urine from three patients were analyzed on day 4 after changing parenteral alimentation to diet, using the same method as mentioned above. The data are shown in Table I. The levels of norharman and harman in the urine of subjects XI and XIII after eating diet for 4 days were higher than those receiving parenteral alimentation. In the case of subject XII, levels of the two $\beta$ carbolines both decreased after eating diet. This may suggest that the amounts of exogenous or endogenous $\beta$-carbolines and their metabolisms differ from person to person.

In the present study, we found that all the $24-\mathrm{hr}$ urine samples from ten healthy volunteers eating normal diet contained norharman and harman. Urine samples from three patients receiving parenteral alimentation were also found to contain the two $\beta$-carbolines. The levels of norharman and harman in urine of healthy volunteers were comparatively higher than those in urine of patients receiving parenteral alimentation. Furthermore, the levels of two $\beta$ carbolines increased in urine of two patients among the three tested after changing from parenteral alimentation to diet. These findings suggest that humans are continuously exposed to norharman and harman, which are derived from exogenous and endogenous sources. However, it is not clarified yet in what proportions of exogenous and endogenous norharman and harman is excreted unchanged in human urine. Since urine is very useful for monitoring the extents of 
human exposure to environmental mutagens and carcinogens, it is important to examine the ratios of the amounts of norharman and harman ingested and formed endogenously to those excreted unchanged or as metabolites in the urine of human.

Acknowledgements. This study was supported by Grants-in-Aid for Cancer Research from the Ministry of Health and Welfare of Japan, and grants from the Bristol-Myers Squibb Foundation and the Smoking Research Foundation.

\section{References}

1) Wakabayashi, K., Yamamoto, T., Tsuji, K., Zenda, H., and Kosuge, T. (1978) Yakugaku Zasshi 98, 904-909 (in Japanese).

2) Poindexter, Jr., E. H., and Carpenter, R. O. (1962) Phytochemistry 1, 215-221.

3) Yasuda, T., Yamaizumi, Z., Nishimura, S., Nagao, M.,
Takahashi, Y., Fujiki, H., Sugimura, T., and Tsuji, K. (1978) Med. GCMS Soc. 3, 97-100 (in Japanese).

4) Nagao, M., Yahagi, T., Honda, M., Seino, Y., Matsushima, T., and Sugimura, T. (1977) Proc. Japan Acad. 53B, 34-37.

5) Nagao, M., Yahagi, T., and Sugimura, T. (1978) Biochem. Biophys. Res. Commun. 83, 373-378.

6) Nakayasu, M., Nakasato, F., Sakamoto, H., Terada, M., and Sugimura, T. (1983) Cancer Lett. 17, 249-255.

7) Madle, E., Obe, G., Hansen, J., and Ristow, H. (19̄81) Mutat. Res. 90, 433-442.

8) Takehisa, S., and Kanaya, N. (1982) Mutat. Res. 101, 165-172.

9) Yamashita, K., Ohgaki, H., Wakabayashi, K., Nagao, M., and Sugimura, T. (1988) Cancer Lett. 42, 179-183.

10) Ushiyama, H., Wakabayashi, K., Hirose, M., Itoh, H., Sugimura, T., and Nagao, M. (1991) Carcinogenesis 12, 1417-1422.

11) Slaytor, M., and McFarlane, I. J. (1968) Phytochemistry 7, 605-611. 